\title{
Best proximity problems for Ćirić type multivalued operators satisfying a cyclic condition
}

\author{
Adrian Magdaş
}

\begin{abstract}
The aim of this paper is to present some best proximity results for multivalued cyclic operators satisfying a Ćirić type condition. Our results extend to the multivalued case some recent results in the literature.
\end{abstract}

Mathematics Subject Classification (2010): 47H04, 47H09, 54H25.

Keywords: Best proximity point, multivalued operator, proximinal set, property UC, comparison function, multivalued Ćirić type cyclic operator, Ulam-Hyers stability.

\section{Introduction and preliminaries}

The standard notations and terminologies in nonlinear analysis will be used throughout this paper.

Let $(X, d)$ be a metric space. We denote:

$P(X):=\{Y \subset X \mid Y$ is nonempty $\} ; P_{b}(X):=\{Y \in P(X) \mid Y$ is bounded $\} ;$

$P_{c l}(X):=\{Y \in P(X) \mid Y$ is closed $\} ; P_{c v}(X):=\{Y \in P(X) \mid Y$ is convex $\}$;

$P_{c p}(X):=\{Y \in P(X) \mid Y$ is compact $\} ; P_{c l, c v}(X):=P_{c l}(X) \cap P_{c v}(X)$.

If $T: Y \subset X \rightarrow P(X)$ is a multivalued operator, then

$$
\operatorname{Graph}(T):=\{(x, y) \in Y \times X \mid y \in T(x)\}
$$

denotes the graph of $T$.

Let us define the following (generalized) functionals used in this paper:

- the diameter functional

$$
\delta: P(X) \times P(X) \rightarrow \mathbb{R}_{+}, \delta(A, B)=\sup \{d(a, b) \mid a \in A, b \in B\} ;
$$

- the gap functional

$$
D: P(X) \times P(X) \rightarrow \mathbb{R}_{+}, D(A, B)=\inf \{d(a, b) \mid a \in A, b \in B\} ;
$$


- the generalized excess functional

$$
\rho: P(X) \times P(X) \rightarrow \mathbb{R}_{+} \cup\{+\infty\}, \rho(A, B)=\sup \{D(a, B) \mid a \in A\} ;
$$

- the generalized Pompeiu-Hausdorff functional

$$
H: P(X) \times P(X) \rightarrow \mathbb{R}_{+} \cup\{+\infty\}, H(A, B)=\max \{\rho(A, B), \rho(B, A)\} .
$$

In 2003, Kirk, Srinivasan and Veeramani generalized Banach's contraction principle introducing the concept of cyclic contraction.

Theorem 1.1. [3] Let $A$ and $B$ be non-empty closed subsets of a complete metric space $(X, d)$. Suppose that $T: A \cup B \rightarrow A \cup B$ is an operator satisfying:

(i) $T(A) \subset B, T(B) \subset A$;

(ii) there exists $k \in(0,1)$ such that for any $x \in A$ and $y \in B$,

$$
d(T(x), T(y)) \leq k d(x, y) .
$$

Then, $T$ has a unique fixed point in $A \cap B$.

The best proximity problem for a cyclic multivalued operator is as follows:

If $(X, d)$ is a metric space, $A, B \in P(X), T: A \cup B \rightarrow P(X)$ is a multivalued operator satisfying the cyclic condition $T(A) \subset B, T(B) \subset A$, then we are interested to find

$$
x^{*} \in A \cup B \text { such that } D\left(x^{*}, T x^{*}\right)=D(A, B) .
$$

$x^{*}$ is said to be a best proximity point of $T$.

Eldred and Veeramani proved in 2006 a theorem (see [1]) which ensures the existence of a best proximity point of cyclic contractions in the framework of uniformly convex Banach spaces.

In 2009, Suzuki, Kikkawa and Vetro introduced the property UC and extended Eldred and Veeramani theorem to metric spaces with the property UC.

Theorem 1.2. [12] Let $(X, d)$ be a metric space and let $A$ and $B$ be nonempty subsets of $X$ such that $(A, B)$ satisfies the property $U C$. Assume that $A$ is complete. Let $T: A \cup B \rightarrow X$ be a cyclic mapping, that is $T(A) \subset B$ and $T(B) \subset A$. Assume that there exists $k \in(0,1)$ such that

$$
d(T(x), T(y)) \leq k \max \{d(x, y), d(x, T(x)), d(y, T(y))\}+(1-k) D(A, B)
$$

for all $x \in A$ and $y \in B$. Then the following hold:

(i) $T$ has a unique best proximity point $z \in A$.

(ii) $z$ is a unique fixed point of $T^{2}$ in $A$.

(iii) $\left(T^{2 n}(x)\right)$ converges to $z$ for every $x \in A$.

(iv) $T$ has at least one best proximity point in $B$.

(v) If $(B, A)$ satisfies the property $U C$, then $T(z)$ is a unique best proximity point in $B$ and $\left(T^{2 n}(y)\right)$ converges to $T(z)$ for every $y \in B$.

The purpose of this paper is to extend Suzuki, Kikkawa and Vetro theorem to multivalued Ćirić type cyclic operator in the framework of metric spaces with the property UC.

We recall now the following notions and results. 
Lemma 1.3. Let $(X, d)$ be a metric space, $A, B \in P(X)$. Then for any $\varepsilon>0$ and for any $a \in A$ there exists $b \in B$ such that

$$
d(a, b) \leq H(A, B)+\varepsilon .
$$

Definition 1.4. Let $(X, d)$ be a metric space, $Y \in P(X)$. We denote

$$
P_{Y}(x)=\{y \in Y \mid d(x, y)=D(x, Y)\} \text { for } x \in X .
$$

The set $Y$ is called proximinal if for any $x \in X, P_{Y}(x)$ is nonempty. If for any $x \in X$, $P_{Y}(x)$ is singleton, then $Y$ is called Chebyshev set.

Obviously, any Chebysev set is proximinal.

We denote $P_{\text {prox }}(X)=\{Y \in P(X) \mid Y$ is proximinal $\}$.

Remark 1.5. Let $(X, d)$ be a metric space. Then

$$
P_{c p}(X) \subset P_{\text {prox }}(X) \subset P_{c l}(X) .
$$

Remark 1.6. [2] Every closed convex subset of a uniformly convex Banach space is a Chebyshev set.

For details concerning the above notions see [7], [9] and [11].

Several types of comparison functions have been considered in literature. In this paper we shall refer only to the following one:

Definition 1.7. [10] A function $\varphi: \mathbb{R}_{+} \rightarrow \mathbb{R}_{+}$is called a comparison function if it satisfies:

(i) $\varphi$ is increasing;

(ii) $\left(\varphi^{n}(t)\right)_{n \in \mathbb{N}}$ converges to 0 as $n \rightarrow \infty$, for all $t \in \mathbb{R}_{+}$.

If the condition (ii) is replaced by:

(iii) $\sum_{k=0}^{\infty} \varphi^{k}(t)<\infty$, for any $t>0$,

then $\varphi$ is called a strong comparison function.

It is evident that a strong comparison function is comparison function.

Lemma 1.8. [9] If $\varphi: \mathbb{R}_{+} \rightarrow \mathbb{R}_{+}$is a comparison function, then $\varphi(t)<t$, for any $t>0, \varphi(0)=0$ and $\varphi$ is continuous at 0 .

Example 1.9. The following functions $\varphi: \mathbb{R}_{+} \rightarrow \mathbb{R}_{+}$are comparison functions:

(1) $\varphi(t)=a t$, where $a \in[0,1[$.

(2) $\varphi(t)=\left\{\begin{array}{l}\frac{1}{2} t, \text { for } t \in[0,1] \\ t-\frac{1}{2}, \text { for } t>1\end{array}\right.$.

(3) $\varphi(t)=a t+\frac{1}{2}[t]$, where $\left.a \in\right] 0, \frac{1}{2}[$.

(4) $\varphi(t)=\frac{t}{1+t}$.

The first three examples are strong comparison functions, and the forth example is a comparison function which is not a strong comparison function. For more examples and considerations on comparison functions see [8], [9]. 
Definition 1.10. [12]. Let $A$ and $B$ be nonempty subsets of a metric space $(X, d)$. Then $(A, B)$ is said to satisfy the property $\mathrm{UC}$ if for $\left(x_{n}\right)_{n \in \mathbf{N}}$ and $\left(z_{n}\right)_{n \in \mathbf{N}}$ sequences in $A$ and $\left(y_{n}\right)_{n \in \mathbf{N}}$ a sequence in $B$ such that $d\left(x_{n}, y_{n}\right) \rightarrow D(A, B)$ and $d\left(z_{n}, y_{n}\right) \rightarrow D(A, B)$ as $n \rightarrow \infty$, then $d\left(x_{n}, z_{n}\right) \rightarrow 0$ as $n \rightarrow \infty$.

The following are examples of pairs of nonempty subsets of a metric space satisfying the property UC.

Proposition 1.11. Any pair of nonempty subsets $(A, B)$ of a metric space $(X, d)$ with $D(A, B)=0$ enjoy the property $U C$.

Proposition 1.12. [1]. Any pair of nonempty subsets $(A, B)$ of a uniformly convex Banach space with A convex enjoy the property $U C$.

\section{Main results}

We start this section by presenting the concept of multivalued Ćirić type cyclic operator.

Definition 2.1. Let $(X, d)$ be a metric space, $A, B \in P(X)$, and $T: A \cup B \rightarrow P(X)$ a multivalued operator. If:

(i) $T(A) \subset B, T(B) \subset A$;

(ii) there exists a comparison function $\varphi: \mathbb{R}_{+} \rightarrow \mathbb{R}_{+}$such that for any $x \in A$, $y \in B$

$$
H(T(x), T(y)) \leq \varphi(M(x, y)-D(A, B))+D(A, B)
$$

where

$$
M(x, y)=\max \left\{d(x, y), D(x, T(x)), D(y, T(y)), \frac{1}{2}[D(x, T(y))+D(y, T(x))]\right\},
$$

then $T$ is called a multivalued Ćirić type cyclic operator.

Example 2.2. The following operators are multivalued Ćirić type cyclic operators:

(1) A multivalued cyclic contraction (see [5]) i.e. a multivalued cyclic operator $T: A \cup B \rightarrow P(X)$ satisfying the condition:

there exists $k \in] 0,1[$ such that for any $x \in A, y \in B$,

$$
H(T(x), T(y)) \leq k d(x, y)+(1-k) D(A, B) .
$$

(2) A multivalued cyclic operator $T: A \cup B \rightarrow P(X)$ satisfying a Chatterjea type condition:

there exists $k \in] 0, \frac{1}{2}[$ such that for any $x \in A, y \in B$,

$$
H(T(x), T(y)) \leq k(D(x, T(y))+D(y, T(x)))+(1-2 k) D(A, B) .
$$

(3) A multivalued cyclic operator $T: A \cup B \rightarrow P(X)$ satisfying a Reich type condition:

there exists $a, b, c \in \mathbb{R}_{+}, s=a+b+c<1$, such that for any $x \in A, y \in B$,

$$
H(T(x), T(y)) \leq a d(x, y)+b D(x, T(x))+c D(y, T(y))+(1-s) D(A, B) .
$$


Our first main result extends the following theorem to the case of multivalued Ćirić type cyclic operator in the setting of proximinal values.

Theorem 2.3. [5] Let $A$ and $B$ be nonempty subsets of a metric space $(X, d)$ such that $(A, B)$ satisfies the property $U C$ and $A$ is complete. Let $T: A \cup B \rightarrow P(X)$ be a multivalued cyclic contraction with closed bounded valued. Then $T$ has a best proximity point in $A$.

The following lemma will be used in the proof of our results.

Lemma 2.4. [5]. Let be $(A, B)$ a pair of nonempty subsets of a metric space $(X, d)$, satisfying the property $U C$, and let be a sequence $\left(x_{n}\right)_{n \in \mathbf{N}}$ in $A$. If there exists a sequence $\left(y_{n}\right)_{n \in \mathbf{N}}$ in $B$ such that $d\left(x_{n}, y_{n}\right) \rightarrow D(A, B)$ and $d\left(x_{n+1}, y_{n}\right) \rightarrow D(A, B)$, then $\left(x_{n}\right)_{n \in \mathbf{N}}$ is a Cauchy sequence.

The first main result of this paper is the following

Theorem 2.5. $(X, d)$ be a complete metric space, $A \in P_{c l}(X), B \in P(X)$, such that $(A, B)$ satisfies the property $U C$. If $T: A \cup B \rightarrow P_{\text {prox }}(X)$ is a multivalued Ćirić type cyclic operator, then the following statements hold:

(i) $T$ has a best proximity point $x_{A}^{*} \in A$;

(ii) there exists a sequence $\left(x_{n}\right)_{n \in \mathbf{N}}$ with $x_{0} \in A$ and $x_{n+1} \in T\left(x_{n}\right)$, such that $\left(x_{2 n}\right)_{n \in \mathbf{N}}$ converges to $x_{A}^{*}$.

Proof. (i) +(ii) We construct a sequence of successive approximations of $T$ starting from an arbitrary $x \in A$ in the following way:

$$
\begin{aligned}
& x_{0}=x \in A ; \\
& x_{n+1} \in T\left(x_{n}\right) \text { such that } d\left(x_{n}, x_{n+1}\right)=D\left(x_{n}, T\left(x_{n}\right)\right), \text { for } n \geq 0,
\end{aligned}
$$

the existence of $x_{n+1}$ being assured by the proximinality of $T\left(x_{n}\right)$.

Then, for $n \geq 1$,

$$
\begin{aligned}
d\left(x_{n}, x_{n+1}\right) & =D\left(x_{n}, T\left(x_{n}\right)\right) \leq H\left(T\left(x_{n-1}\right), T\left(x_{n}\right)\right) \\
& \leq \varphi\left(M\left(x_{n-1}, x_{n}\right)-D(A, B)\right)+D(A, B),
\end{aligned}
$$

where

$$
\begin{aligned}
M\left(x_{n-1}, x_{n}\right)= & \max \left\{d\left(x_{n-1}, x_{n}\right), D\left(x_{n-1}, T\left(x_{n-1}\right)\right), D\left(x_{n}, T\left(x_{n}\right)\right),\right. \\
& \left.\left.\frac{1}{2}\left[D\left(x_{n-1}, T\left(x_{n}\right)\right)+D\left(x_{n}, T\left(x_{n-1}\right)\right)\right]\right\}\right) .
\end{aligned}
$$

Notice that

$$
D\left(x_{n-1}, T\left(x_{n-1}\right)\right)=d\left(x_{n-1}, x_{n}\right) \text { and } D\left(x_{n}, T\left(x_{n-1}\right)\right)=0 .
$$

Using the triangle inequality,

$$
\begin{aligned}
D\left(x_{n-1}, T\left(x_{n}\right)\right) & \leq d\left(x_{n-1}, x_{n}\right)+D\left(x_{n}, T\left(x_{n}\right)\right) \\
& =d\left(x_{n-1}, x_{n}\right)+d\left(x_{n}, x_{n+1}\right), n \geq 1 .
\end{aligned}
$$

So

$$
\frac{1}{2}\left[D\left(x_{n-1}, T\left(x_{n}\right)\right)+D\left(x_{n}, T\left(x_{n-1}\right)\right)\right] \leq \frac{1}{2}\left[d\left(x_{n-1}, x_{n}\right)+d\left(x_{n}, x_{n+1}\right)\right],
$$


and

$$
M\left(x_{n-1}, x_{n}\right) \leq \max \left\{d\left(x_{n-1}, x_{n}\right), d\left(x_{n}, x_{n+1}\right)\right\}, n \geq 1 .
$$

Denoting $z_{n}=d\left(x_{n}, x_{n+1}\right)-D(A, B)$ and using the monotonicity of $\varphi,(2.1)$ becomes

$$
z_{n} \leq \varphi\left(\max \left\{z_{n-1}, z_{n}\right\}\right) \text {, for } n \geq 1 \text {. }
$$

Because $\varphi(t)<t$, for any $t>0$, we get

$$
z_{n} \leq \varphi\left(z_{n-1}\right) \text {, for any } n \geq 1 \text {. }
$$

Thus

$$
z_{n} \leq \varphi^{n-1}\left(z_{1}\right) \rightarrow 0, \text { so } d\left(x_{n}, x_{n+1}\right) \rightarrow D(A, B) \text { when } n \rightarrow \infty
$$

Since

$$
\left(x_{2 n}\right)_{n \in \mathbf{N}} \subset A,\left(x_{2 n+2}\right)_{n \in \mathbf{N}} \subset A \text {, and }\left(x_{2 n+1}\right)_{n \in \mathbf{N}} \subset B,
$$

by Lemma 2.4, $\left(x_{2 n}\right)_{n \in \mathbf{N}}$ is a Cauchy sequence in the complete metric space $X$. Hence, the Cauchy sequence $\left(x_{2 n}\right)_{n \in \mathbf{N}}$ converges to a point $x_{A}^{*}$ which lies in $A$ because $\left(x_{2 n}\right)_{n \geq 0} \subset A$ and $A$ is closed.

For $n \geq 1$, we have

$$
\begin{aligned}
& D(A, B) \leq d\left(x_{A}^{*}, x_{2 n-1}\right) \leq d\left(x_{A}^{*}, x_{2 n}\right)+d\left(x_{2 n}, x_{2 n-1}\right), \\
& \quad \text { so } d\left(x_{A}^{*}, x_{2 n-1}\right) \rightarrow D(A, B) \text { when } n \rightarrow \infty . \\
& D(A, B) \leq D\left(x_{2 n}, T\left(x_{A}^{*}\right)\right) \\
& \leq H\left(T\left(x_{2 n-1}\right), T\left(x_{A}^{*}\right)\right) \\
& \leq \varphi\left(M\left(x_{2 n-1}, x_{A}^{*}\right)-D(A, B)\right)+D(A, B) \\
&< M\left(x_{2 n-1}, x_{A}^{*}\right) \\
&= \max \left\{d\left(x_{2 n-1}, x_{A}^{*}\right), D\left(x_{2 n-1}, T\left(x_{2 n-1}\right)\right), D\left(x_{2 n}, T\left(x_{2 n}\right)\right),\right. \\
&\left.\frac{1}{2}\left[D\left(x_{2 n-1}, T\left(x_{2 n}\right)\right)+D\left(x_{2 n}, T\left(x_{2 n-1}\right)\right)\right]\right\}
\end{aligned}
$$

Each term from maximum's expression tends to $D(A, B)$ :

$$
\begin{aligned}
d\left(x_{2 n-1}, x_{A}^{*}\right) & \rightarrow D(A, B) ; \\
D\left(x_{2 n-1}, T\left(x_{2 n-1}\right)\right) & =d\left(x_{2 n-1}, x_{2 n}\right) \rightarrow D(A, B) ; \\
D\left(x_{2 n}, T\left(x_{2 n}\right)\right) & =d\left(x_{2 n}, x_{2 n+1}\right) \rightarrow D(A, B) ; \\
D\left(x_{2 n}, T\left(x_{2 n-1}\right)\right) & =0 ; \\
\frac{1}{2}\left[D\left(x_{2 n-1}, T\left(x_{2 n}\right)\right)\right] & \leq \frac{1}{2}\left[d\left(x_{2 n-1}, x_{2 n}\right)+D\left(x_{2 n}, T\left(x_{2 n}\right)\right)\right] \rightarrow D(A, B)
\end{aligned}
$$

Thus

$$
D\left(x_{2 n}, T\left(x_{A}^{*}\right)\right) \rightarrow D(A, B)
$$

Then we have

$$
D(A, B) \leq D\left(x_{A}^{*}, T\left(x_{A}^{*}\right)\right) \leq d\left(x_{A}^{*}, x_{2 n}\right)+D\left(x_{2 n}, T\left(x_{A}^{*}\right)\right) \rightarrow D(A, B) .
$$

Therefore

$$
D\left(x_{A}^{*}, T\left(x_{A}^{*}\right)\right)=D(A, B) .
$$


Remark 2.6. If in Theorem $2.5 D(A, B)=0$, then we obtain a fixed point result, see Theorem 2.7 in [4].

Theorem 2.7. Let $(X, d)$ be a complete metric space, $A, B \in P_{c l}(X)$, such that the pairs $(A, B)$ and $(B, A)$ satisfy the property $U C$. Let $T: A \cup B \rightarrow P_{\text {prox }}(X)$ be a multivalued operator. Then the following statements hold:

(i) If $T$ is a multivalued Ćirić type cyclic operator, then $T$ has at least one best proximity point in $A$ and at least one best proximity point in $B$;

(ii) If $T$ satisfies the following stronger condition:

for any $x \in A, y \in B$,

$$
\delta(T(x), T(y)) \leq \varphi(M(x, y)-D(A, B))+D(A, B),
$$

then there exist a best proximity $x_{A}^{*} \in A$ and a best proximity point $x_{B}^{*} \in B$ such that:

$$
d\left(x_{A}^{*}, x_{B}^{*}\right) \leq \sup \{t \geq 0 \mid t-\varphi(t) \leq 3 D(A, B)\} .
$$

Proof. (i) It is a consequence of Theorem 2.5.

(ii) $d\left(x_{A}^{*}, x_{B}^{*}\right) \leq D\left(x_{A}^{*}, T\left(x_{A}^{*}\right)\right)+\delta\left(T\left(x_{A}^{*}\right), T\left(x_{B}^{*}\right)\right)+D\left(x_{B}^{*}, T\left(x_{B}^{*}\right)\right)$

$$
\begin{aligned}
= & 2 D(A, B)+\delta\left(T\left(x_{A}^{*}\right), T\left(x_{B}^{*}\right) \leq\right. \\
\leq & 2 D(A, B)+\varphi\left(\operatorname { m a x } \left\{d\left(x_{A}^{*}, x_{B}^{*}\right), D\left(x_{A}^{*}, T\left(x_{A}^{*}\right)\right), D\left(x_{B}^{*}, T\left(x_{B}^{*}\right)\right),\right.\right. \\
& \left.\left.\frac{1}{2}\left[D\left(x_{A}^{*}, T\left(x_{B}^{*}\right)\right)+D\left(x_{B}^{*}, T\left(x_{A}^{*}\right)\right)\right]\right\}-D(A, B)\right)+D(A, B) \\
\leq & 3 D(A, B)+\varphi\left(\operatorname { m a x } \left\{d\left(x_{A}^{*}, x_{B}^{*}\right), D(A, B), D(A, B),\right.\right. \\
& \left.\left.\frac{1}{2}\left[d\left(x_{A}^{*}, x_{B}^{*}\right)+D(A, B)+d\left(x_{B}^{*}, x_{A}^{*}\right)+D(A, B)\right]\right\}-D(A, B)\right) \\
= & 3 D(A, B)+\varphi\left(d\left(x_{A}^{*}, x_{B}^{*}\right)\right)
\end{aligned}
$$

Thus, $d\left(x_{A}^{*}, x_{B}^{*}\right)-\varphi\left(d\left(x_{A}^{*}, x_{B}^{*}\right)\right) \leq 3 D(A, B)$.

Corollary 2.8. Let $X$ be a uniformly convex Banach space,

$$
A, B \in P_{c l, c v}(X), T: A \cup B \rightarrow P_{c l, c v}(X)
$$

be a multivalued operator. Then the following statements hold:

(i) If $T$ is a multivalued Cirić type cyclic operator, then $T$ has at least one best proximity point in $A$ and at least one best proximity point in $B$;

(ii) If $T$ satisfies the following stronger condition:

for any $x \in A, y \in B$,

$$
\delta(T(x), T(y)) \leq \varphi(M(x, y)-D(A, B))+D(A, B),
$$

then there exist a best proximity $x_{A}^{*} \in A$ and a best proximity point $x_{B}^{*} \in B$ such that:

$$
\left\|x_{A}^{*}-x_{B}^{*}\right\| \leq \sup \{t \geq 0 \mid t-\varphi(t) \leq 3 D(A, B)\} .
$$

Proof. (i) By Remark 1.6, any closed and convex set is proximinal.

Since $A$ and $B$ are convex, by Proposition 1.12 , the pairs $(A, B)$ and $(B, A)$ satisfy the property UC.

Applying Theorem 2.7 we get the existence of a best proximity point $x_{A}^{*} \in A$ and a best proximity point $x_{B}^{*} \in B$.

(ii) It is an immediate consequence of Theorem 2.7. 
If, in Theorem 2.7, $\varphi$ is a subadditive strong comparison function, then the condition that the multivalued operator takes proximinal values can be removed. More precisely, we obtain the second main result, as follows.

Theorem 2.9. Let $(X, d)$ be a complete metric space, $A, B \in P_{c l}(X)$, such that $(A, B)$ satisfies the property $U C$. If $T: A \cup B \rightarrow P(X)$ is a multivalued Ciric type cyclic operator, with a subadditive strong comparison function $\varphi$, then the following statements hold:

(i) $T$ has a best proximity point $x_{A}^{*} \in A$;

(ii) there exists a sequence $\left(x_{n}\right)_{n \in \mathbf{N}}$ with $x_{n+1} \in T\left(x_{n}\right)$ starting from an arbitrary $\left(x_{0}, x_{1}\right) \in \operatorname{Graph}(T)$, such that $\left(x_{2 n}\right)_{n \in \mathbf{N}}$ converges to $x_{A}^{*}$.

Proof. (i)+(ii) Let $(x, y) \in G \operatorname{raph}(T)$ be arbitrary. We construct a sequence of successive approximations of $T$ starting from $(x, y)$ in the following way:

$$
x_{0}=x \in A \text { and } x_{1}=y \in T(x) \subseteq T(A) \subseteq B .
$$

If $d\left(x_{0}, x_{1}\right)>D(A, B)$ then $\varphi\left(z_{0}\right)<z_{0}$, where $z_{0}:=d\left(x_{0}, x_{1}\right)-D(A, B)$.

For $\left.\varepsilon_{1} \in\right] 0, z_{0}-\varphi\left(z_{0}\right)$ [ there exists $x_{2} \in T\left(x_{1}\right) \subseteq T(B) \subseteq A$ such that

$$
d\left(x_{1}, x_{2}\right) \leq H\left(T\left(x_{0}\right), T\left(x_{1}\right)\right)+\varepsilon_{1} .
$$

If $d\left(x_{1}, x_{2}\right)>D(A, B)$ then $\varphi\left(z_{1}\right)<z_{1}$, where $z_{1}:=d\left(x_{1}, x_{2}\right)-D(A, B)$.

For $\left.\varepsilon_{2} \in\right] 0, \min \left\{\varepsilon_{1}, z_{1}-\varphi\left(z_{1}\right)\right\}$ [ there exists $x_{3} \in T\left(x_{2}\right) \subseteq T(A) \subseteq B$ such that

$$
d\left(x_{2}, x_{3}\right) \leq H\left(T\left(x_{1}\right), T\left(x_{2}\right)\right)+\varepsilon_{2} .
$$

Following this procedure in the case $z_{n-1}:=d\left(x_{n-1}, x_{n}\right)-D(A, B)>0, n \geq 2$, we choose

$$
\left.\varepsilon_{n} \in\right] 0, \min \left\{\varepsilon_{n-1}, z_{n-1}-\varphi\left(z_{n-1}\right)\right\}[\text {, for } n \geq 2 .
$$

There exists $x_{n+1} \in T\left(x_{n}\right)$ such that

$$
d\left(x_{n}, x_{n+1}\right) \leq H\left(T\left(x_{n-1}\right), T\left(x_{n}\right)\right)+\varepsilon_{n}, n \geq 1,
$$

the existence of $x_{n+1}$ being assured by Lemma 1.3.

Since $\mathrm{T}$ is a multivalued Ćirić type cyclic operator, using the same reasoning as in Theorem 2.5, we have

$$
z_{n} \leq \varphi\left(\max \left\{z_{n-1}, z_{n}\right\}\right)+\varepsilon_{n}, \text { for } n \geq 1 .
$$

Using (2.2), we obtain

$$
z_{n}<\varphi\left(\max \left\{z_{n-1}, z_{n}\right\}\right)+z_{n-1}-\varphi\left(z_{n-1}\right), \text { for } n \geq 1 .
$$

We suppose that $z_{n-1} \leq z_{n}$. Using the subadditivity of $\varphi$ and Lemma 1.8,

$$
\varphi\left(z_{n}\right)=\varphi\left(z_{n}-z_{n-1}+z_{n-1}\right) \leq \varphi\left(z_{n}-z_{n-1}\right)+\varphi\left(z_{n-1}\right) \leq z_{n}-z_{n-1}+\varphi\left(z_{n-1}\right),
$$

so $z_{n} \geq \varphi\left(z_{n}\right)+z_{n-1}-\varphi\left(z_{n-1}\right)$ which contradicts $(2.4)$. 
We have $z_{n} \leq z_{n-1}$ and (2.3) becomes

$$
\begin{aligned}
z_{n} \leq & \varphi\left(z_{n-1}\right)+\varepsilon_{n} \\
\leq & \left.\varphi\left(\varphi\left(z_{n-2}\right)+\varepsilon_{n-1}\right)\right)+\varepsilon_{n} \\
\leq & \varphi^{2}\left(z_{n-2}\right)+\varphi\left(\varepsilon_{n-1}\right)+\varepsilon_{n} \\
& \cdots \\
\leq & \varphi^{n}\left(z_{0}\right)+\sum_{k=0}^{n-1} \varphi^{k}\left(\varepsilon_{n-k}\right) \\
\leq & \varphi^{n}\left(z_{0}\right)+\sum_{k=0}^{n-1} \varphi^{k}\left(\varepsilon_{1}\right) \rightarrow 0, \text { when } n \rightarrow \infty .
\end{aligned}
$$

Then

$$
d\left(x_{n}, x_{n+1}\right) \rightarrow D(A, B) \text { when } n \rightarrow \infty .
$$

Applying Lemma 2.4 for the sequences

$$
\left(x_{2 n}\right)_{n \in \mathbf{N}} \subset A,\left(x_{2 n+2}\right)_{n \in \mathbf{N}} \subset A \text {, and }\left(x_{2 n+1}\right)_{n \in \mathbf{N}} \subset B,
$$

results that $\left(x_{2 n}\right)_{n \in \mathbf{N}}$ is a Cauchy sequence. Because the metric space $X$ is complete and $A$ is closed, the sequence $\left(x_{2 n}\right)_{n \geq 0} \subset A$ converges to a point $x_{A}^{*} \in A$. Using the same reasoning as in Theorem 2.5,

$$
D\left(x_{2 n}, T\left(x_{A}^{*}\right)\right) \rightarrow D(A, B), \text { when } n \rightarrow \infty .
$$

Then we have

$$
D(A, B) \leq D\left(x_{A}^{*}, T\left(x_{A}^{*}\right)\right) \leq d\left(x_{A}^{*}, x_{2 n}\right)+D\left(x_{2 n}, T\left(x_{A}^{*}\right)\right) \rightarrow D(A, B) .
$$

Therefore

$$
D\left(x_{A}^{*}, T\left(x_{A}^{*}\right)\right)=D(A, B) .
$$

If in the above construction, there exists $k \geq 1$ such that $d\left(x_{k-1}, x_{k}\right)=D(A, B)$, then

$$
D(A, B) \leq D\left(x_{k-1}, T\left(x_{k-1}\right)\right) \leq d\left(x_{k-1}, x_{k}\right)=D(A, B)
$$

so $x_{k-1}$ is a best proximity point of $\mathrm{T}$.

We will show that, in this situation, $x_{k}$ is also a best proximity point of $\mathrm{T}$.

$$
D\left(x_{k}, T\left(x_{k}\right)\right) \leq H\left(T\left(x_{k-1}\right), T\left(x_{k}\right)\right) \leq \varphi\left(M\left(x_{k-1}, x_{k}\right)-D(A, B)\right)+D(A, B) .
$$

where

$$
\begin{aligned}
M\left(x_{k-1}, x_{k}\right)= & \max \left\{d\left(x_{k-1}, x_{k}\right), D\left(x_{k-1}, T\left(x_{k-1}\right)\right), D\left(x_{k}, T\left(x_{k}\right)\right)\right. \\
& \left.\left.\frac{1}{2}\left[D\left(x_{k-1}, T\left(x_{k}\right)\right)+D\left(x_{k}, T\left(x_{k-1}\right)\right)\right]\right\}\right) \\
\leq & \max \left\{D(A, B), D\left(x_{k}, T\left(x_{k}\right)\right)\right. \\
& \left.\left.\frac{1}{2}\left[d\left(x_{k-1}, x_{k}\right)+D\left(x_{k}, T\left(x_{k}\right)\right)\right]\right\}\right) \\
\leq & D\left(x_{k}, T\left(x_{k}\right)\right) .
\end{aligned}
$$


Thus $D\left(x_{k}, T\left(x_{k}\right)\right)-D(A, B) \leq \varphi\left(D\left(x_{k}, T\left(x_{k}\right)\right)-D(A, B)\right)$, which means

$$
D\left(x_{k}, T\left(x_{k}\right)\right)=D(A, B) .
$$

There exists $x_{k+1} \in T\left(x_{k}\right)$ such that

$$
d\left(x_{k}, x_{k+1}\right)=D\left(x_{k}, T\left(x_{k}\right)\right)=D(A, B),
$$

From now on, following this procedure we construct the terms of our sequence $\left(x_{n}\right)_{n \in \mathbf{N}}$ with $x_{n+1} \in T\left(x_{n}\right)$ such that

$$
d\left(x_{n}, x_{n+1}\right)=D\left(x_{n}, T\left(x_{n}\right)\right)=D(A, B), \text { for any } n \geq k .
$$

From this point, the proof runs in the same manner as in the case

$$
d\left(x_{n}, x_{n+1}\right)>D(A, B) \text {, for any } n \geq 1 .
$$

Hereinafter we define and study the generalized Ulam-Hyers stability of the best proximity problem (1.1) for a cyclic multivalued operator.

Definition 2.10. Let $(X, d)$ be a complete metric space, $A, B \in P(X)$. Let $T: A \cup B \rightarrow$ $P(X)$ be a multivalued operator satisfying the cyclic condition $T(A) \subset B, T(B) \subset A$. The best proximity problem (1.1) is called generalized Ulam-Hyers stable if there exists $\psi: \mathbb{R}_{+} \rightarrow \mathbb{R}_{+}$increasing, continuous at 0 , with $\psi(0)=0$ and there exists $c>0$ such that for any $\varepsilon>0$ and $x \in B$ with

$$
D(x, T(x)) \leq \varepsilon+D(A, B),
$$

there exists a solution $x_{A}^{*} \in A$ of (1.1) such that

$$
d\left(x, x_{A}^{*}\right) \leq \psi(\varepsilon)+c \cdot D(A, B) .
$$

Our stability result is the following.

Theorem 2.11. Let $(X, d)$ be a complete metric space, $A \in P_{c l}(X), B \in P(X)$, such that $(A, B)$ satisfies the property $U C$ and $\varphi$ be a comparison function. Let $T: A \cup B \rightarrow$ $P_{\text {prox }}(X)$ be a multivalued operator. Assume that:

(i) $T(A) \subset B, T(B) \subset A$;

(ii) for any $x \in A, y \in B$,

$$
\delta(T(x), T(y)) \leq \varphi(\max \{D(x, T(x)), D(y, T(y))\}-D(A, B))+D(A, B) .
$$

Then the best proximity problem (1.1) is generalized Ulam-Hyers stable.

Proof. $T$ is a multivalued Ćirić type cyclic operator, so the best proximity problem has at least one solution $x_{A}^{*} \in A$.

$$
\begin{aligned}
d\left(x, x_{A}^{*}\right) \leq & D(x, T(x))+\delta\left(T(x), T\left(x_{A}^{*}\right)\right)+D\left(x_{A}^{*}, T\left(x_{A}^{*}\right)\right) \\
\leq & \varepsilon+D(A, B)+\varphi\left(\max \left\{D(x, T(x)), D\left(x_{A}^{*}, T\left(x_{A}^{*}\right)\right)\right\}\right. \\
& -D(A, B))+2 D(A, B) \\
\leq & \varepsilon+\varphi(\max \{\varepsilon+D(A, B), D(A, B)\}-D(A, B))+3 D(A, B) .
\end{aligned}
$$

In conclusion,

$$
d\left(x, x_{A}^{*}\right) \leq \varepsilon+\varphi(\varepsilon)+3 D(A, B),
$$

proving that the best proximity problem (1.1) is generalized Ulam-Hyers stable. 


\section{References}

[1] Eldred, A.A., Veeramani, P., Existence and convergence of best proximity points, J. Math. Anal. Appl., 323(2006), no. 2, 1001-1006.

[2] Fletcher, J., Moors, W.B., Chebyshev sets, J. Aust. Math. Soc., 98 (2015), 161-231.

[3] Kirk, W.A., Srinivasan, P.S., Veeramani, P., Fixed points for mappings satisfying cyclical contractive conditions, Fixed Point Theory, 4(2003), no. 1, 79-89.

[4] Magdas, A., A fixed point theorem for Ćirić type multivalued operators satisfying a cyclical condition, J. Nonlinear Convex Anal., 17(2015), no. 6, 1109-1116.

[5] Neammanee, K., Kaewkhao, A., Fixed points and best proximity points for multi-valued mapping satisfying cyclical condition, International Journal of Mathematical Sciences and Applications, 1(2011), 1-9.

[6] Păcurar, M., Rus, I.A., Fixed point theory for cyclic $\varphi$-contractions, Nonlinear Anal., 72(2010), 1181-1187.

[7] Petruşel, G., Cyclic representations and periodic points, Stud. Univ. Babeş-Bolyai Math., 50(2005), no. 3, 107-112.

[8] Rus, I.A., Generalized Contractions and Applications, Cluj University Press, 2001.

[9] Rus, I.A., Petruşel, A., Petruşel, G., Fixed Point Theory, Cluj University Press, 2008.

[10] Rus, I.A., Şerban, M.A., Some generalizations of a Cauchy lemma and applications, Topics in Mathematics, Computer Science and Philosophy (Şt. Cobzaş Ed.), Cluj University Press, 2008, 173-181.

[11] Singh, S.P., Watson, B., Srivastava, P., Fixed Point Theory and Best Approximation: the KKM-map Principle, Kluwer Academic Publishers, Dordrecht, 1997.

[12] Suzuki, T., Kikkawa, M., Vetro, C., The existence of best proximity points in metric spaces with the property UC, Nonlinear Anal., 71(2009), no. 7-8, 2918-2926.

Adrian Magdaş

Babeş-Bolyai University

Faculty of Mathematics and Computer Science

Kogălniceanu Street, No. 1

400084 Cluj-Napoca, Romania

e-mail: amagdas@yahoo.com 